\title{
COMPARISON OF EFFICACY OF N- ACETYLCYSTEINE WITH SALBUTAMOL NEBULIZATION IN ACUTE BRONCHIOLITIS
}

\author{
DR. SIDRA MAHMOOD, MBBS \\ NISHTAR HOSPITAL, MULTAN, PAKISTAN. \\ DR. SYEDA FATIMA ZAHRA GARDEZI, MBBS \\ NISHTAR HOSPITAL, MULTAN, PAKISTAN. \\ DR. ARSLAN AHMAD, MBBS \\ SERVICES HOSPITAL , LAHORE, PAKISTAN.
}

\begin{abstract}
Background; A substantial proportion of children will experience at least one episode with bronchiolitis, and as much as $2-3 \%$ of all children will be hospitalized with bronchiolitis during their first year of life. Bronchiolitis is the most common reason for hospitalization of children in many countries, challenging both economy, area and staffing in paediatric departments. Objective; To compare efficacy of N-acetylcysteine nebulization versus salbutamol nebulization in children with acute bronchiolitis. Material and Methods; The study cases were randomly divided into 2 groups by draws methods. Group A, each child was nebulized with $20 \mathrm{mg}$ NAC in $3 \mathrm{ml}$ of $0.9 \%$ of saline while group B was nebulized with $2.5 \mathrm{mg}$ salbutamol in $3 \mathrm{ml}$ of $0.9 \%$ saline solution. Patients of each group were nebulized three times a day ( 8 hours apart) for 5 days. These patients were closely monitored for the severity of the disease daily and clinical severity score was employed to record any improvement in both cases. All the data was entered and analyzed using SPSS-18. Results; Of these 390 study cases, 228 (58.5\%) were boys while $162(41.5 \%)$ were girls. Mean age of our study cases was $7.92 \pm 5.18$ months . Most of the study cases i.e. $264(67.7 \%)$ were from poor social background and mothers of most of these children were less educated as $85.6 \%$ of the mothers of these children were having their educational status equal/less than matriculation. Mean hospital stay in our study was $4.73 \pm 0.829$ days. Mean baseline clinical severity score was $5.52 \pm 813$. Mean clinical severity score after therapy was $1.85 \pm 0.812$ (with minimum clinical severity score was 1 while maximum was score was 4). Clinical severity score in group A was $1.21 \pm 0.405$ while in group B was $2.49 \pm 0.578(\mathrm{p}=0.000)$. Conclusion; Our study results support the use $\mathrm{N}-$ acetylcysteine nebulization in children with acute bronchiolitis as compared with salbutamol nebulization. $\mathrm{N}$ - acetylcysteine nebulization was found to be more effective in improving clinical severity score and reducing duration of hospitalization. Its use was safe, reliable and no adverse side effects were noted.
\end{abstract}

Keywords; Acute Bronchiolitis, Salbutamol, N - acetylcysteine.

DOI: $10.7176 / \mathrm{JMPB} / 55-12$

Publication date:May $31^{\text {st }} 2019$

\section{Introduction;}

Bronchiolitis is an acute inflammatory obstruction of small airways (bronchioles and alveoli) in children that occurs in first two years of life ${ }^{1}$. It is characterized by fever, rhinitis, cough, tachypnea, expiratory wheeze and increased respiratory effort. Acute viral bronchiolitis is one of the most common causes of hospitalization during infancy with respiratory syncytial virus (RSV) being the major causative agent $(85 \%)^{2-4}$.

Globally, among healthy, full term infants, $80 \%$ of hospitalizations occur in the first year of life and $50 \%$ of hospitalizations occur in children 1-3 months of age. In Pakistan, acute respiratory illness (ARI) is the leading cause of death in young children responsible for $20-30 \%$ of all child death under age 5 years. It occurs in a seasonal pattern, with peak incidence in the winter to spring months. Risk factors for early onset disease and subsequent hospitalization include low birth weight, prematurity, lower socioeconomic group, crowded living conditions, parental smoking, absence of breast-feeding, and day care centers. Majority of the children present with respiratory distress and wheezing ${ }^{5-7}$. Pathophysiologically bronchiolitis is an infection of the bronchiolar epithelium with subsequent profound submucosal and advential oedema, increased secretion of mucus, peribronchiolar mononuclear infiltration and epithelial cell necrosis ${ }^{8-10}$. These changes obstruct flow in the small airways leading to hyperinflation, atelectasis and wheezing ${ }^{8}$. N-acetylcysteine (NAC) is an antioxidant that 
cleaves disulphide bonds by converting them to 2 sulphuryl groups ${ }^{11}$. This action results in the breakup of mucoproteins in lung mucus, reducing chain lengths and thinning mucus, mucolytics like NAC has been studies in the treatment of various diseases states such as pulmonary in nature ( cystic fibrosis, chronic bronchitis, idiopathic pulmonary fibrosis and critically ill states) $)^{9,12-15}$.

A study has reported significant decrease in clinical severity score by using NAC nebulization versus salbutamol i.e. it was decreased from $5.38 \pm 2.62$ to $0.88 \pm 1.08$ with NAC and from $4.68 \pm 2.2$ to $1.90 \pm 1.32$ after completion the course of therapy for 5 days $^{6}$. Similarly mean duration for hospitalization was also short with NAC nebulization i.e. $4.36 \pm 1.66$ days versus $4.98 \pm 2.6$ days in case of salbutamol nebulization ${ }^{6}$.

This study was done to determine outcome of NAC compared with those of salbutamol in the patients of acute bronchiolitis as there is very much limited data available of this topic.

\section{Patients and Methods;}

Three hundred and ninety hospitalized children with acute bronchiolitis were registered in this randomized controlled trial from Department of Pediatrics, Nishtar Hospital Multan. Patients with underlying bronchopulmonary dysplasia, chronic lung diseases, neuromuscular impairment, immunodeficiency or congenital heart disease, patients with previous history of malignancy and those already taking NAC or salbutamol therapy were excluded from our study. Informed consent was taken from the parents of each child, baseline information like heart rate, respiratory rate, wheeze score and clinical severity score were taken. Acute Bronchiolitis was defined as Children having clinical severity score more than 4 with fever (more than $101 \mathrm{~F}^{0}$ ) and cough within 2 days. These study cases were randomly divided into 2 groups by draws methods (Group A and Group B with 190 patients in each group). Group A, each child was nebulized with $20 \mathrm{mg}$ NAC in $3 \mathrm{ml}$ of $0.9 \%$ of saline while group B was nebulized with $2.5 \mathrm{mg}$ salbutamol in $3 \mathrm{ml}$ of $0.9 \%$ saline solution. Patients of each group were nebulized three times a day ( 8 hours apart) for 5 days. These patients were closely monitored for the severity of the disease daily and clinical severity score was employed to record any improvement in both cases. Final outcome was measured at day five. All the data was entered and analyzed using SPSS-18. Descriptive statistics was applied to calculate mean and standard deviation for age of patients, clinical severity score and duration of hospital stays. Frequencies and percentage was tabulated for the categorical variables like gender and age groups. Student's t test was applied to compare clinical severity and hospital stay in both groups.

\section{Results;}

Our study included a total 390 children with acute bronchiolitis who met inclusion criteria of our study. Of these 390 study cases, $228(58.5 \%)$ were boys while $162(41.5 \%)$ were girls. Mean age of our study cases was $7.92 \pm 5.18$ months ranging from 2 months to 24 months. Mean age of our study cases in group A was 8.07 \pm 5.46 months while that of group B was $7.77 \pm 4.91$ months $(p=0.579)$ while $318(81.5 \%)$ were aged less than 12 months. Most of the study cases i.e. 264 (67.7\%) were from poor social background and mothers of most of these children were less educated as $85.6 \%$ of the mothers of these children were having their educational status equal/less than matriculation. Mean hospital stay in our study was $4.73 \pm 0.829$ days ranging from 3 days to 7 days). Mean baseline clinical severity score was $5.52 \pm 813$ (with minimum baseline clinical severity score was 5 and maximum was 8). Mean clinical severity score after therapy was $1.85 \pm 0.812$ (with minimum clinical severity score was 1 while maximum was score was 4). Clinical severity score in group A was $1.21 \pm 0.405$ while in group B was $2.49 \pm 0.578(\mathrm{p}=0.000)$.

\section{Discussion;}

Our study included a total 390 children with acute bronchiolitis who met inclusion criteria of our study. Of these 390 study cases, 228 (58.5\%) were boys while $162(41.5 \%)$ were girls. Different studies have documented male gender predominance in patients with acute bronchiolitis. A study conducted by Arif et al ${ }^{16}$ from Lahore reported $68 \%$ boys with acute bronchiolitis which is similar to our study results. Another study from Faisalabad by Ahmed et al ${ }^{17}$ reported 1.4:1 male to female ratio which is showing male gender predominance. Jacobs et al ${ }^{18}$ reported $69 \%$ boys with acute bronchiolitis showing male gender predominance. However Naz et al ${ }^{6}$ from Lahore reported $40 \%$ boys with acute bronchiolitis and $60 \%$ girls which is quite different from our study results. Mean age of our study cases was $7.92 \pm 5.18$ months ranging from 2 months to 24 months. Mean age of our study cases in group A was $8.07 \pm 5.46$ months while that of group B was $7.77 \pm$ 4.91 months $(p=0.579)$. Our study results have indicated that majority of our study cases i.e. $318(81.5 \%)$ were aged less than 12 months. Airf et al ${ }^{16}$ from Lahore reported $5.43 \pm 9.44$ months mean age of the children with acute bronchiolitis which is close to our study results. Ahmed et al ${ }^{17}$ from Faisalabad reported $7.6 \pm 4.7$ months 
mean age which is close to our study results. Jacobs et al ${ }^{18}$ reported $6.0 \pm 3.9$ months mean age, similar to our results. Naz et al ${ }^{6}$ reported 3 months mean age which is a bit lower than that of our study results. Most of the study cases i.e. $264(67.7 \%)$ were from poor social background and mothers of most of these children were less educated as $85.6 \%$ of the mothers of these children were having their educational status equal/less than matriculation. Similar findings have been reported by Ahmed et al ${ }^{17}$ from Faisalabad. Mean hospital stay in our study was $4.73 \pm 0.829$ days (with minimum hospital stay was 3 days while maximum hospital stay was 7 days). Flores et al ${ }^{19}$ reported $5.4 \pm 2.1$ days hospital stay with acute bronchiolitis which is close to our study findings. $\mathrm{Naz}$ et al ${ }^{6}$ reported $4.67 \pm 2.2$ days mean duration of hospitalization which is same as that of our study results. Mean baseline clinical severity score was $5.52 \pm 813$ (with minimum baseline clinical severity score was 5 and maximum was 8). A study conducted in Lahore by Ejaz et al ${ }^{20}$ reported $5.68 \pm 0.73$ clinical severity score which is in compliance with our study results. Jacobs et al ${ }^{18}$ reported $5.7 \pm 1.8$ mean score which is similar to that of our study results. Mean clinical severity score after therapy was $1.85 \pm 0.812$ (with minimum clinical severity score was 1 while maximum was score was 4). Clinical severity score in group A was $1.21 \pm 0.405$ while in group B was $2.49 \pm 0.578(\mathrm{p}=0.000)$. Naz et al ${ }^{6}$ also reported similar results as mean score in group A (treated with $\mathrm{N}$ - acetylcystein) was $0.88 \pm 1.08$ while in group B treated with salbutamol was $1.90 \pm 1.32$. These results are same as that of our findings showing $\mathrm{N}$ - acetylcystein to be more effective.

\section{Conclusion;}

Our study results support the use $\mathrm{N}$ - acetylcysteine nebulization in children with acute bronchiolitis as compared with salbutamol nebulization. $\mathrm{N}$ - acetylcysteine nebulization was found to be more effective in improving clinical severity score and reducing duration of hospitalization significantly. Its use was safe, reliable and no adverse side effects were noted.

\section{References;}

1. Uyar M, Kuyucu N, Tezcan S, Aslan G, Tasdelen B. Determination of the frequency of human bocavirus and other respiratory viruses among 0-2 years age group children diagnosed as acute bronchiolitis. Mikrobiyol Bul. 2014;48(2):242-58.

2. Frey U, von Mutius E. The challenge of managing wheezing in infants. N Engl J Med. 2009;360:2130-3.

3. Calvo C, Pozo F, García-García ML, Sanchez M, Lopez-Valero M, Pérez-Breña P, et al . Detection of new respiratory viruses in hospitalized infants with bronchiolitis: a three-year prospective study. Acta Paediatr. 2010;99(6):883-7.

4. Mansbach JM, Piedra PA, Teach SJ, Sullivan AF, Forgey T, Clark S, et al. Prospective multicenter study of viral etiology and hospital length of stay in children with severe bronchiolitis. Arch Pediatr Adolesc Med. 2012;166(8):700-6.

5. Iqbal SMJ, Afzal MF, Sultana MA. Acute bronchiolitis; epidemiological and clinical study. Ann. 2009;15(4):203-5.

6. Naz F, Raza AB, Ijaz I, Kazi MY. Effectiveness of nebulized N-acetylcysteine solution in children with acute bronchiolitis. J Coll Physicians Surg Pak. 2014;24(6):408-11.

7. Ansari K, Sakran M, Davidson BL, Sayyed RE, Mahjoub H, Ibrahim K. Nebulized $5 \%$ or 3\% hypertonic or $0.9 \%$ saline for treating acute bronchiolitis in infants. J Pediatr. 2010;157:630-4.

8. Burgel R, Bergeron A, Blic JD, Bonniaud P, Bourdin A, Chanez P, et al. Small airways diseases, excluding asthma and COPD: an overview. Eur Respir Rev 2013;22:131-47.

9. Fahy JV, Dickey BF. Airway mucus function and dysfunction. N Eng J Med. 2010;363:2233-44.

10. Kim IK ${ }^{1}$, Phrampus E, Sikes K, Pendleton J, Saville A, Corcoran T, et al. Helium-oxygen therapy for infants with bronchiolitis: a randomized controlled trial. Arch Pediatr Adolesc Med 2011;165:1115-22.

11. Everard $\mathrm{ML}^{1}$, Hind $\mathrm{D}^{2}$, Ugonna $\mathrm{K}^{3}$, Freeman $\mathrm{J}^{4}$, Bradburn $\mathrm{M}^{2}$, Dixon $\mathrm{S}^{2}$, et al. Saline in acute bronchiolitis RCT and economic evaluation: hypertonic saline in acute bronchiolitis - randomised controlled trial and systematic review. Health Technol Assess. 2015 Aug;19(66):1-130. 
12. Roqué i Figuls $M^{1}$, Giné-Garriga M, Granados Rugeles C, Perrotta C, Vilaró J. Chest physiotherapy for acute bronchiolitis in paediatric patients between 0 and 24 months old. Cochrane Database Syst Rev. 2016 Feb 1;2:CD004873.

13. Jat KR, Chawla D. Surfactant therapy for bronchiolitis in critically ill infants. Cochrane Database Syst Rev 2012;9:CD009194.

14. Stockman LJ, Curns AT, Anderson LJ, Fischer-Langley G. Respiratory syncytial virus-associated hospitalizations among infants and young children in the United States, 1997-2006. Pediatr Infect Dis J. 2012;31:5-9

15. Øymar $\mathrm{K}^{1}$, Skjerven HO, Mikalsen IB. Acute bronchiolitis in infants, a review. Scand J Trauma Resusc Emerg Med. 2014 Apr 3;22:23. doi: 10.1186/1757-7241-22-23.

16. Arif A, Tajammul A. Acute Bronchiolitis - a clinical study Pak Paed J. 1998;22(4):175-7.

17. Ahmad S, Aamir S, Ahmad S. Acute bronchiolitis in children; epidemiologic and clinical features. Professional Med J. 2013;20(5):707-12.

18. Jacobs $\mathrm{JD}^{1}$, Foster M, Wan J, Pershad J. 7\% Hypertonic saline in acute bronchiolitis: a randomized controlled trial. Pediatrics. 2014 Jan;133(1):e8-13.

19. Flores $\mathrm{P}^{1}$, Mendes $\mathrm{AL}^{1}$, Neto $\mathrm{AS}^{1}$. A randomized trial of nebulized $3 \%$ hypertonic saline with salbutamol in the treatment of acute bronchiolitis in hospitalized infants. Pediatr Pulmonol. 2016 Apr;51(4):418-25.

20. Ejaz I, Siddique A, Rathore AW, Khan HI. Hypertonic Saline (3\%) vs Normal Saline (0.9\%) Nebuliztion for Acute Viral Bronchiolitis: A Randomized Control Trial. Pak Paed J. 2015;39(4):248-51. 